http://jmscr.igmpublication.org/home/ ISSN (e)-2347-176x ISSN (p) 2455-0450 crossref DOI: https://dx.doi.org/10.18535/jmscr/v8i7.87

\author{
Journal Of Medical Science And Clinical Research \\ IGM Publication \\ An Official Publication of IGM Publication
}

\title{
Godwin's Modification of Mandibular Labial Vestibuloplasty: A Case Report
}

\section{Authors \\ Dr Chandulal D. Dhalkari ${ }^{1}$, Dr Maya S. Indurkar ${ }^{2}$, Dr Onkar A. Bagade 3* $^{*}$ Dr Amit R. Parate ${ }^{4}$}

${ }^{1}$ BDS, MDS, Maharashtra University of Health Science. Dept. of Periodontology \& Implantology, Professor \& PG Guide at Government Dental College \& Hospital - Aurangabad

${ }^{2}$ BDS, MDS, Maharashtra University of Health Science. Dept. of Periodontology \& Implantology, HOD \&

Professor at Government Dental College \& Hospital - Aurangabad

${ }^{3}$ BDS, $3{ }^{\text {rd }}$ year PG Student at the Maharashtra University of Health Science. Dept. of Periodontology \& Implantology, BDS \& $3^{\text {rd }}$ yr PG Student at Government Dental College \& Hospital - Aurangabad

${ }^{4}$ Associate Professor, Dept. of Oral Medicine and Radiology, Government Dental College and Hospital, Aurangabad 431001

*Corresponding Author

Dr Onkar A. Bagade

\begin{abstract}
A 50-year-old male patient was referred from the Department of Prosthodontics for inadequate vestibular depth with inadequate attached tissue in the mandibular anterior labial region. The mandibular labial vestibule was extended by Godwin's modification of Kazanjian vestibuloplasty technique followed by prefabricated acrylic denture plate for retention and prevention of relapse. The procedure led a considerable gain in the width of the attached gingiva which was maintained even 3 months after the surgical procedure. This technique produces a consistent and predictable increase in the width of the attached gingiva and may be successfully used in the treatment of inadequate vestibular depth.
\end{abstract}

\section{Introduction}

Ridge extension is an essential pre-prosthetic surgery for a successful denture fabrication in cases of inadequate vestibular depth. The following three basic techniques have been described for ridge extension as submucosal vestibuloplasty, ${ }^{1} \quad$ secondary epithelialization vestibuloplasty, ${ }^{2-3}$ and soft tissue grafting vestibuloplasty. $^{4-6}$ Vestibuloplasty repositions mucosa, muscle insertions of depressor labii inferioris and mentalis in case of mandibular labial region and leads to increased denture flange area and stability of prosthesis. ${ }^{2}$ The present literature states that minimum ridge height required for vestibular surgery ranged from 15-20 $\mathrm{mm}$. ${ }^{7}$ The success has been obtained with various methods.

This case report describes a case of Godwin's modification of Kazanjian vestibuloplasty. 


\section{Case Report}

A 50-year male patient was referred from the Department of Prosthodontics for inadequate vestibular depth with inadequate attached tissue in the mandibular anterior labial region to the Department of Periodontology. The patient was systemically healthy and haemogram was normal. Since the resorption of the alveolar ridge was relatively little and the vertical dimension of the mandible was of sufficient height as assessed with an OPG, submucous surgical operation on the mandible under local anaesthesia was decided on. Godwin's modification of Kazanjian vestibuloplasty was performed under local anaesthesia (Lignocaine-2\% with 1:80000 adrenaline) with bilateral mental nerve blocks and local infiltration. Approximately 12-15 mm externally from the crest of the alveolar ridge a horizontal incision was made on the oral mucous membrane of the lip. This incision was extended to the premolar region bilaterally and two vertical incisions were given to extend it towards the crest of the alveolar ridge (Figure1). The mucous membrane flap outlined with an incision was carefully separated from the underlying submucosa and reflected towards the alveolar crest. It is a mucous membrane flap and not mucoperiosteal flap. After raising the flap, the underlying submucosal tissue, the muscle fibers and the periosteum were resected away, leaving the bare bone exposed. The excision was carried down to a depth where it can be assured that the contracture of the wound would result in desired the depth of the vestibule. (Figure 2)After smoothening the rough bony spots on the bony ridge, the mucous membrane flap was placed against the bare bone of the labial aspect of the alveolar ridge and sutured with 5-0 reverse cutting vicryl sutures at the of the vestibule. (Figure 3)

Resultant raw surface was covered using betadine moistened gauze which was left for secondary epithelialization. Coe-pack periodontal dressing was placed on the ridge. (Figure 4) The patient was given a prefabricated mandibular acrylic denture plate to wear for one week continuously except at night during initial phase of healing to prevent relapse. A flexible rubber tubing placement with percutaneous suturing at the depth of the vestibule was replaced with an acrylic denture plate in this case. The patient was put on postoperative oral antibiotic and antiinflammatory drugs (Cap.Amoxicillin-500mg 8th hourly and Tab. Ketorol DT, 12th hourly for 5 days). Patients was instructed to maintain soft diet and warm saline rinses after meals for minimum duration of four weeks. The good results with increased vestibular depth and increased attached tissue were observed at three months.

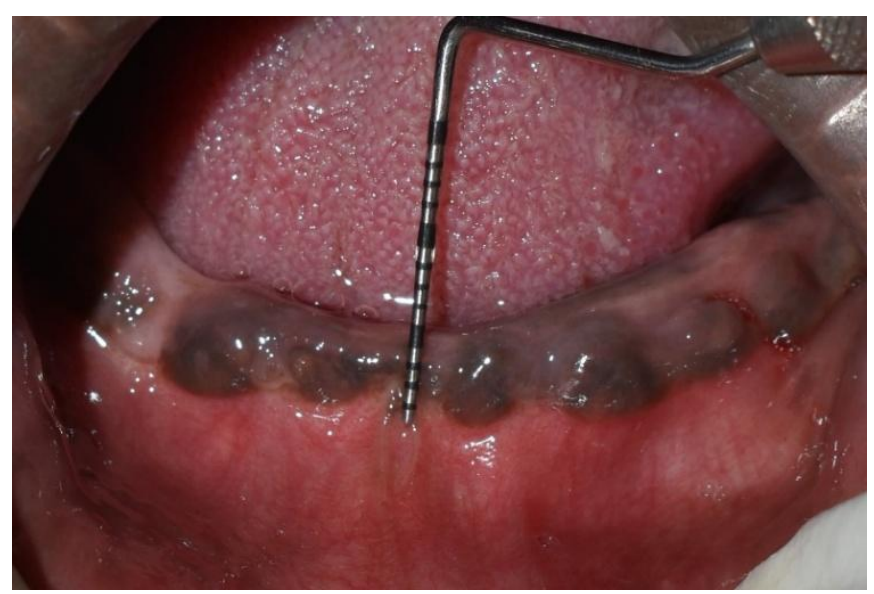

Fig.1 Preoperative view showing inadequate vestibular depth and inadequate attached tissue with attachment of tissue near the crest of the ridge

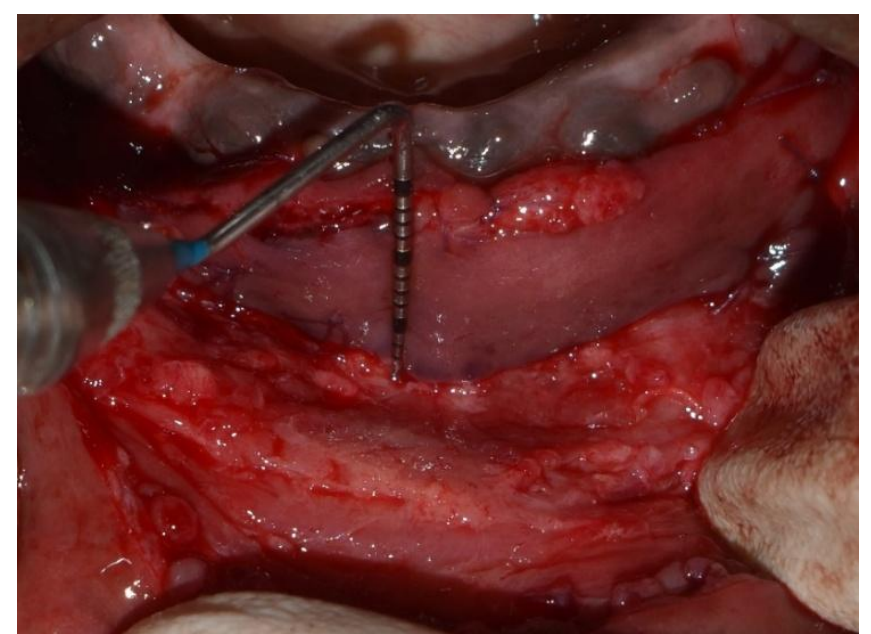

Fig.2 Flap reflection, subperiosteal dissection and checking of vestibular extension 


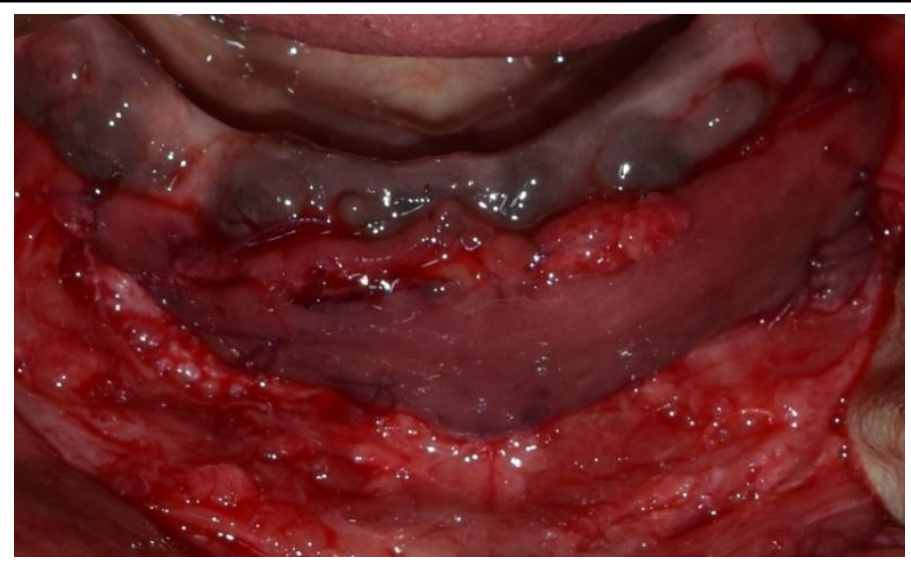

Fig.3 Suturing completed.

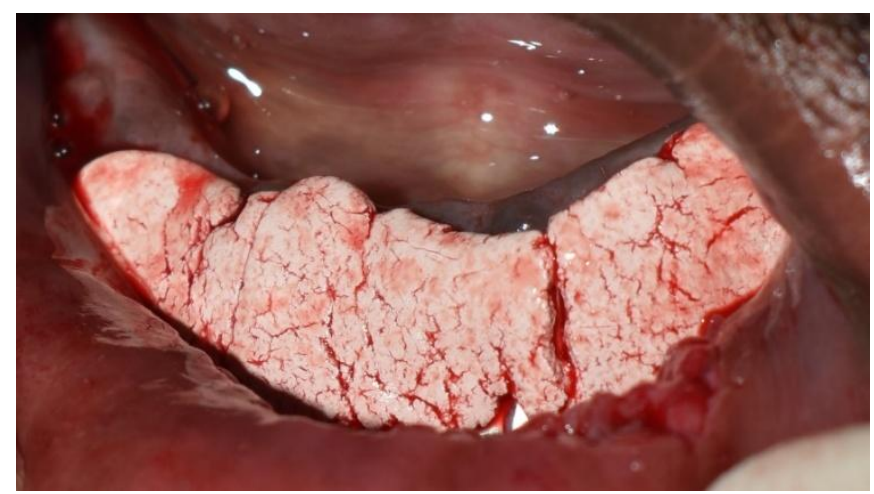

Fig.4 Coe-pack periodontal dressing placed.

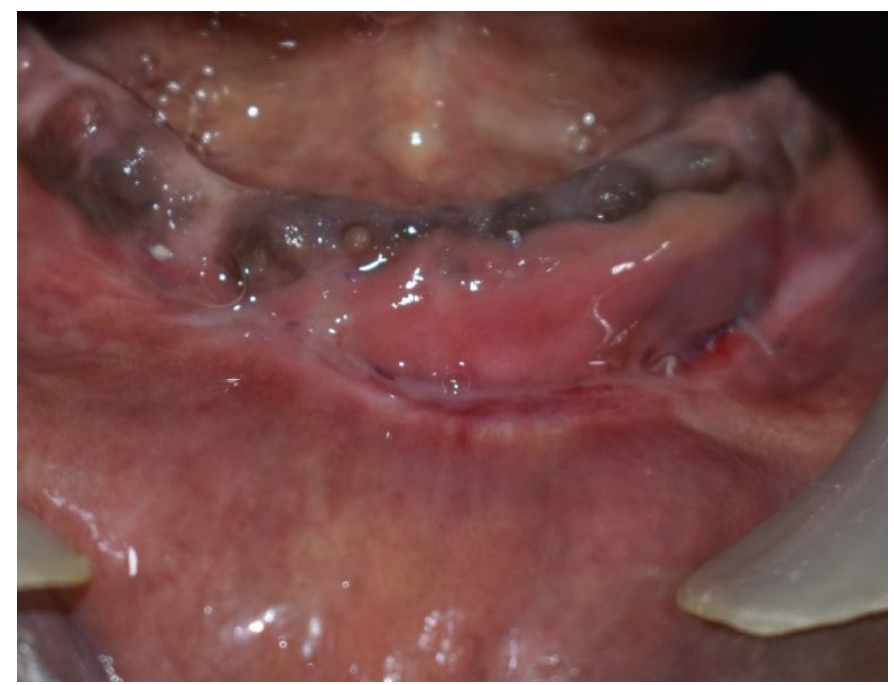

Fig. 5 Three months postoperative results with minimum wound contraction and increased vestibular depth.

\section{Discussion}

Vestibuloplasty is the surgical procedure carried out to restore alveolar ridge heights by lowering muscle attachment on the buccal, labial, and lingual aspects of the residual ridges. ${ }^{8}$ In 1935 , Kazanjian proposed a method for ridge extension where the submucosal flap pedicled on the alveolar ridge taken from the lip was sutured over the intact periosteum in the depth of the vestibule. The raw lip area healed by secondary intention. ${ }^{2}$ Then in 1947, Godwin modified Kazanjian technique by sub periosteal stripping instead of supra periosteal dissection for vestibular extension. Vestibular mucosa was placed against the bare bone and sutured to connective tissue by excising or apically relocating the periosteum and connective tissue. ${ }^{3}$ The scar contracture resulted in decreased depth of the vestibule in the above techniques. $^{7,9}$ In 1953, Clark proposed a vestibuloplasty procedure in which the flap from the alveolar ridge was pedicled on the lip with resultant secondary intention healing of labial surface of alveolar ridge to solve this problem. ${ }^{10}$ The contraction of raw surface over the bone was less as compared to the contraction of raw surface on the epithelium. It was the basis of Clark's technique. ${ }^{1,7,10}$ In 1968, Tortorelli recommended horizontal fenestration of the periosteum along the base of the newly created vestibule to limit the loss of vestibular depth that occurs after Clark's vestibuloplasty. ${ }^{8}$ The Lip switch vestibuloplasty was advocated to overcome drawbacks of Kazanjian technique where mucosal flap covered the bare bone and periosteal flap covered the labial side. Here, epithelization of periosteum occurs in 2-3 weeks without scarring. ${ }^{8}$ The grafting vestibuloplasty was introduced to overcome disadvantages associated with healing and patient discomfort in the previous techniques. ${ }^{7}$ The free gingival graft procedure requires harvesting the graft from a donor site, usually the palate. The use of palatal donor tissue, especially when large areas must be grafted, increases morbidity and the risk of surgical complications. In addition, adequate amounts of donor tissue may not be available from the palate. ${ }^{7}$ The skin graft has hair and sebaceous glands and causes patient discomfort. ${ }^{7}$ 


\section{Conclusion}

If performed correctly and in judiciously selected cases Godwin's modification of mandibular labial vestibuloplasty can be expected to have a prognosis with good results in terms of increase in depth of the vestibule and attached tissue thereby increasing the chances of successful denture delivery.

\section{Acknowledgments}

Authors acknowledge the contribution of Department of Periodontology, Government Dental College and Hospital, Aurangabad, Maharashtra, India

Conflict of interest: The authors have no conflict of interest to disclose.

\section{References}

1. Obwegeser H: Surgical preparation of the maxilla for prosthesis. J Oral Surg 22:127, 1964

2. Kazanjian VH. Surgery as an aid to more efficient service with prosthetic dentures. The Journal of the American Dental Association (1922). 1935 Apr 1;22(4):56681.

3. Godwin JG. Submucous surgery for better denture service. The Journal of the American Dental Association. 1947 May 15;34(10):678-86.

4. Trauner R: Alveoloplasty with ridge extension on lingual side of the lower jaw to solve the problem of a lower dental prosthesis. J Oral Surg 5:340, 1952

5. Steinhauser EW. Free transplantation of oral mucosa for improvement of denture retention. J. Oral. Surg.. 1969;27:955-61.

6. Hall HD. Free grafts of palatal mucosa in mandibular vestibuloplasty. J Oral Surg. 1970;28:565.

7. Starshak TJ, Sanders B. Preprosthetic oral and maxillofacial surgery. Mosby; 1980.
8. Chari H, Shaik KV. Preprosthetic surgery: review of literature. IJSS. 2016 Sep;3(4):10.

9. Shelton DW: Critical review of preprosthetic surgery, in Irby WB: Current Advances in Oral Surgery, Vol II. St Louis, MO, Mosby, 1977, p 362

10. Clark Jr HB. Deepening of labial sulcus by mucosal flap advancement. Journal of oral surgery. 1953 Apr;11(2):165. 